\title{
Objetivos de Seleção e Valores Econômicos de Características de Importância Econômica para um Sistema de Produção de Leite a Pasto na Região Sudeste*
}

\author{
Vera Lúcia Cardoso1, José Ramos Nogueira², Aníbal Eugênio Vercesi Filho³, Lenira El Faro, \\ Nilson Carlos Lima ${ }^{5}$
}

\begin{abstract}
RESUMO - Como parte de um estudo para o desenvolvimento de estratégias de seleção envolvendo animais da raça Holandesa e mestiços (Holandês x Zebu) na região sudeste do Brasil, foram derivados valores econômicos para volume de leite (V), produção de gordura (G) e de proteína (P), idade ao primeiro parto (IPP), peso adulto (PA) e vida útil no rebanho (VU), para um sistema de produção de leite a pasto com vacas mestiças (Holandês x Zebu). O manejo alimentar foi baseado no pastejo rotacionado de capim-elefante durante a estação chuvosa e suplementação volumosa de silagem de milho na época da seca. O fornecimento de concentrados foi na base de $1 \mathrm{~kg}$ de concentrado para 2,5 kg de leite, quando as produções individuais excediam $6 \mathrm{~kg}$ de leite/dia. Foram realizadas análises de sensibilidade para avaliar o impacto das mudanças no sistema de pagamento e variações no preço do leite sobre os valores econômicos das características estudadas. Foram também derivados valores econômicos considerando-se como fonte alternativa de suplementação volumosa na seca a mistura cana-de-açúcar + uréia. Os valores econômicos (US\$), de acordo com o sistema de pagamento corrente para V, G, P, IPP, PA e VU, foram, respectivamente, 0,$15 ;-0,48 ;-0,31 ;-0,11 ; 0,08$ e 0,04 . Os resultados das análises de sensibilidade são apresentados e discutidos.
\end{abstract}

Palavras-chave: melhoramento genético, modelos bio-econômicos, objetivos de seleção, sistemas de produção de leite, valor econômico

\section{Breeding Goals and Economic Values for Pasture Based Milk Production Systems in the Southeast Region of Brazil}

\begin{abstract}
As part of a preliminary study on the design of a breeding program involving Holstein Friesian and crossbred cattle (Holstein $x$ Zebu) in the Southeast region of Brazil, economic values for milk volume (V), fat (F) and protein (P) production, age at first calving (AFC), mature body weight (MBW) and herd life (HL) were derived for a pasture based milk production system of crossbred cattle (Holstein $\mathrm{x}$ Zebu). The feeding regime was based on rotational grazing of elephantgrass during the rainy season and grazing plus maize silage during the dry season. Concentrates were fed when daily individual productions exceed 6-kg milk ( $1 \mathrm{~kg}$ concentrate: 2.5 $\mathrm{kg}$ milk). Sensitivity analyses were carried out to evaluate the effect of the change of payment system and milk price variation on economic values of the traits. Economic values were also derived for an alternative source of roughage supplementation based on the mixture of sugar cane plus urea. The economic values (US\$) derived for the current payment system for V, F, P, AFC, MBW and HL were, respectively: $0.15 ;-0.48 ;-0.31 ;-0.11 ; 0.08$ and 0.04 . Results of sensitivity analyses are presented and discussed.
\end{abstract}

Key Words: genetic improvement, bio-economic models, breeding goal, milk production systems, economic value

\section{Introdução}

O objetivo do melhoramento é modificar o mérito genético dos animais das gerações futuras de modo que estes produzam mais eficientemente, quando comparados à geração presente, levando-se em conta as circunstâncias naturais, sociais e de mercado vigentes no futuro (Groen et al., 1997). A definição "eficientemente" é relativa ao objetivo geral, ou objetivo de seleção, que é definido como a combinação de características economicamente importantes de acordo com o sistema de produção. Desde que se deseje, em última instância, maximizar o lucro da atividade, o objetivo de seleção deve levar em conta as fontes de receita do sistema, como os produtos, a venda do excedente de animais de reposição e de

\footnotetext{
* Apoio financeiro: Fundação de Amparo à Pesquisa do Estado de São Paulo - FAPESP.

1 Pesquisador Científico. Apta Regional, PRDTA Centro Leste, Ribeirão Preto-SP. E.mail: vlcardoso.ddd@apta.sp.gov.br

2 Pesquisador Científico. Apta Regional, PRDTA Centro Leste, Ribeirão Preto-SP. E.mail: jnogueira.ddd@apta.sp.gov.br

3 Pesquisador Científico. Apta Regional, PRDTA Nordeste Paulista, Mococa-SP. E.mail: joaopinheirobr@yahoo.com.br

4 Pesquisador Científico. Apta Regional, PRDTA Centro Leste, Ribeirão Preto-SP. E.mail: lenira.ddd@apta.sp.gov.br

5 Zootecnista, ex-bolsista de iniciação científica da FAPESP. E.mail: nilson.lima@ourofinovet.com.br
} 
descarte, bem como os componentes de custo de produção do sistema (alimentação, instalações etc.). Assim, pode-se inferir que o objetivo de seleção é maximizar o melhoramento do mérito econômico. Este pode ser definido de várias maneiras, como por exemplo, lucro por indivíduo, lucro por fazenda, eficiência econômica, entre outros (Gibson \& Van Arendonk, 1999).

A definição do objetivo de seleção constitui um passo fundamental no desenvolvimento de um programa de melhoramento genético, uma vez que ele descreve a expectativa do que deve ser melhorado. Portanto, para o seu estabelecimento deve-se identificar, na medida do possível, todos os caracteres biológicos que influenciam as receitas e despesas do sistema de produção. Em geral, este objetivo inclui as variáveis econômicas tradicionais, como as quantidades produzidas de leite, gordura, proteína, carne, ovos, lã, mas também pode incluir outros aspectos funcionais, que embora não aumentem as quantidades de produtos, seu melhoramento pode ocasionar a diminuição dos custos de produção (Groen et al., 1997).

Em sistemas de produção de leite com base em rebanhos comerciais, a principal fonte de receita é a venda do leite, além da venda dos bezerros, do excedente de novilhas para reposição e de vacas descartadas para abate. Nos países onde existe o pagamento diferenciado do leite pela qualidade, o objetivo de seleção inclui a produção de gordura e proteína. No Brasil, não existe uma política de pagamento diferenciado pela qualidade do leite, e sim padrões mínimos a serem atendidos tanto em relação à composição, quanto aos aspectos de sanidade que, caso não sejam atendidos, ocasionam penalizações no valor pago ao produtor. Contudo, alguns laticínios, interessados na aquisição de matéria-prima de melhor padrão, em grande parte, para atender a produção de derivados de alta qualidade e abastecer grandes centros consumidores, já realizam algum tipo de pagamento diferenciado pelo teor de gordura, proteína e/ou sólidos totais. Além disso, alguns fazendeiros, interessados em agregar valor ao seu produto, produzem algum tipo de derivado lácteo na propriedade e, com isso, têm interesse na mudança da composição do leite. Além das características de produção de leite, outros caracteres que influenciam a eficiência econômica de um sistema de produção de leite pela diminuição dos custos de produção são: a idade ao primeiro parto, cuja diminuição resulta na redução dos custos de criação de novilhas, podendo, ainda, resultar em maior vida útil; o peso do animal adulto (supondo-se que animais mais pesados apresentam maiores exigências para manutenção e por conseguinte, maiores custos com alimentação) e a própria vida útil, que determina a taxa de reposição de um rebanho e, portanto, os custos com aquisição de novilhas de reposição.

A principal ferramenta para derivar valores econômicos é a modelagem ou análise sistêmica. Duas abordagens de análise sistêmica podem ser distinguidas - a abordagem positiva, ou avaliação de dados, e a abordagem normativa, ou simulação de dados (James \& Ellis, 1979). No primeiro caso, são usados dados técnicos e econômicos observados e no segundo, equações de lucro e modelos bio-econômicos. Em ambos os casos, o objetivo é a obtenção da receita líquida, obtida pela diferença entre a receita obtida com o produto- custo estimado de produção. A modelagem de sistemas de produção animal, fornece boa compreensão da sensibilidade dos valores econômicos às circunstâncias de produção no nível do animal, do rebanho, da fazenda e níveis superiores (Groen \& Van Arendonk, 1997).

Mediante o uso de equações de lucro, Vercesi Filho et al. (2000) estimaram pesos econômicos para características de produção de leite, reprodução e resistência à mastite, com base em informações de desempenho produtivo e econômico de um rebanho mestiço (Holandês x Zebu) de uma propriedade leiteira em Minas Gerais. Madalena (2000) calculou valores econômicos para produção de leite ("veículo"), gordura e proteína, levando em consideração dois sistemas de pagamento de leite no Paraná e Minas Gerais. Para o sistema de pagamento do Paraná, que contempla o teor de gordura e proteína na composição do preço do leite, o valor econômico dos três componentes foram positivos, sendo similares para gordura e proteína e ambos mais altos que o valor do "veículo", enquanto para o sistema de pagamento de Minas Gerais, somente o valor do "veículo" foi positivo.

A técnica da programação dinâmica (PD), combinada ao uso de modelos bio-econômicos, também tem sido empregada para determinação de valores econômicos para diversas características, tanto de produção e reprodução, quanto funcionais (Boichard et al., 1990; Dekkers, 1991; Veerkamp et al., 1995; Dekkers et al., 1998; Vargas, 2000).

O objetivo do presente trabalho foi identificar características relevantes a serem incluídas em objetivos de seleção, mediante a derivação de valores

R. Bras. Zootec., v.33, n.2, p.320-327, 2004 
econômicos, para um sistema de produção de leite a pasto com vacas mestiças $\mathrm{F}_{1}$ (Holandês $\mathrm{x}$ Zebu) levando em conta as circunstâncias de produção e comercialização do Estado de São Paulo.

\section{Material e Métodos}

Foi adotado um modelo de sistema de produção com base no pastejo rotacionado, supondo-se um rebanho estabilizado de animais mestiços Holandês x Zebu.

Para descrever receitas e custos do sistema, utilizou-se o modelo bio-econômico desenvolvido por Van Arendonk (1985), e adaptado para as circunstâncias de produção da região Sudeste (Cardoso et al., 1998), o qual simula produções de leite, gordura e proteína e pesos de vacas, de acordo com a ordem do parto (variando da primeira a $12^{\mathrm{a}}$ lactação), nível de produção de leite (considerando-se 15 níveis de produção, variando de 70 a $130 \%$ dos valores estabelecidos como médios para o grupamento genético em estudo) e duração dos intervalos de partos referentes às lactações em curso e anteriores (ambos variando de 11 a 16 meses). Foram calculadas as receitas provenientes da venda do leite, de bezerros e dos animais descartados (valor de abate da carcaça); os custos com alimentação e a receita líquida. Estes dados foram gerados em base mensal, de acordo com os parâmetros, preços e custos estabelecidos para descrever as circunstâncias de produção do presente estudo (mais detalhes sobre o modelo são fornecidos por Cardoso et al.,1998).

As informações de desempenho dos animais mestiços (Holandês x Zebu) foram obtidas da literatura (Madalena et al. 1990a,1990b; Madalena et al., 1995, Lemos et al., 1996; Lemos et al., 1997). Os preços médios dos componentes de produção (insumos e produtos) foram calculados a partir de dados mensais referentes ao período de 1999-2000 (Anuário de informações Estatísticas da Agricultura, 2000, 2001). Os parâmetros fisiológicos e preços incluídos no modelo bio-econômico encontram-se na Tabela 1.

Os custos com alimentação foram calculados supondo-se um sistema alimentar com base no pastejo rotacionado durante todo o ano, com suplementação de silagem na seca, resultando em consumo médio anual de volumoso de $65 \%$ de capim-elefante (Penisteum purpureum) e 35\% de silagem de milho. Para fins de obtenção do valor de $1 \mathrm{~kg}$ de matéria seca da pastagem, foram calculados os custos anuais com formação e manutenção de um hectare de pastagem, supondo-se adubação nitrogenada de 150 $\mathrm{kg} / \mathrm{ha}$. Assumiu-se o fornecimento de concentrados para produções de leite diárias acima de $6 \mathrm{~kg}$ de leite, na proporção de $1 \mathrm{~kg}$ de concentrado: $2,5 \mathrm{~kg}$ de leite. O conteúdo de energia dos alimentos foi obtido, na medida do possível, de dados de composição de alimentos da literatura brasileira.

Os custos com a criação de bezerros (machos e fêmeas) até os 12 meses incluíram alimentação, custos veterinários, mão de obra e instalações, que totalizaram US $\$ 96,00$ por animal. Foi considerada taxa de sobrevivência até 12 meses de idade de $92 \%$

Tabela 1 - Sumário dos parâmetros e preços usados para descrever o sistema de produção de leite com fêmeas mestiças $F_{1}$

Table 1 - Summary of parameters and prices used to describe the $F_{1}$ cows in the production system

\begin{tabular}{|c|c|}
\hline $\begin{array}{l}\text { Parâmetros } \\
\text { Parameters }\end{array}$ & $\begin{array}{r}\text { Valores } \\
\text { Values }\end{array}$ \\
\hline Produção de leite ${ }^{\mathrm{a}}(\mathrm{kg})$ & 3700 \\
\hline Milk yield & \\
\hline Porcentagem de gordura ${ }^{a}(\%)$ & 4,1 \\
\hline Fatpercentage & \\
\hline Porcentagem de proteína ${ }^{a}(\%)$ & 3,2 \\
\hline Protein percentage & \\
\hline Idade ao primeiro parto (meses) & 33 \\
\hline Age at first calving & \\
\hline Taxa de mortalidade de bezerros até 12 meses (\%) & 8 \\
\hline Mortality rate of 12-month calves & \\
\hline Peso vivo ${ }^{a}(\mathrm{~kg})$ & 550 \\
\hline Mature body weight & \\
\hline Rendimento de carcaça - fêmeas (\%) & 49 \\
\hline Dressing percentage-females & \\
\hline Preços (US\$) & \\
\hline Prices & \\
\hline Leite (kg) & 0,20 \\
\hline Milk & \\
\hline Carcaça (kg) & 1,15 \\
\hline Carcass & \\
\hline Machos e fêmeas / um ano de idade & 140,00 \\
\hline Males / females 12-month old & \\
\hline Novilha de reposição & 500,00 \\
\hline Replacement heifer & \\
\hline Custo de criação de bezerros até 12 meses & 96,00 \\
\hline $\begin{array}{l}\text { Rearing costs (up to } 12 \text { months) } \\
\text { Silagem de milho (kg MS) }\end{array}$ & 0,062 \\
\hline Maize silage & \\
\hline Capim-elefante (kg MS) & 0,017 \\
\hline Elephantgrass & \\
\hline Concentrado (kg MS) & 0,20 \\
\hline Concentrate & \\
\hline
\end{tabular}


(Madalena et al., 1995). Taxa de juros de 6\% ao ano foi cobrada sobre o valor da carcaça. Os custos veterinários somaram US\$36,00/vaca/ano (medicamentos, vacinas, desinfetantes, assistência veterinária etc). Supôs-se que os custos com mão-de-obra eram fixos para um tamanho de rebanho fixo com determinado nível de produção e práticas de manejo e que mudanças marginais nas características consideradas não afetariam estes custos. Assim, os mesmos não foram considerados.

Os custos anuais com reposição foram calculados de acordo com a vida útil obtida para cada caso, assumindo-se a aplicação da estratégia de reposição que maximizou o retorno econômico, supondo-se o rebanho estabilizado. Para tal foi usado o modelo de programação dinâmica (PD), desenvolvido por Van Arendonk \& Dijkhuizen (1985) e modificado por Van Arendonk para as circunstâncias de produção da região sudeste do Brasil (Cardoso et al., 1998). De acordo com esta técnica, os valores esperados para os fluxos de caixa referentes às vacas presentes no rebanho e às candidatas a novilhas de reposição foram comparados mês a mês, em um horizonte de planejamento de 15 anos. A receita líquida média anual esperada foi calculada a partir do valor presente esperado do fluxo de caixa anual de uma novilha de reposição incorporada no rebanho, durante o período estabelecido como horizonte de planejamento, sob a estratégia ótima. Mais detalhes sobre o modelo são fornecidos por Cardoso et al. (1998).

Com base em Lemos et al. (1996) e Madalena (comunicação pessoal), assumiu-se que as probabilidades de descarte involuntário para a situação básica corresponderiam a $25 \%$ dos níveis usados para estudo similar com a raça Holandesa (Cardoso et al., 1998).

Levando-se em conta que uma das vantagens destes animais é a longevidade, considerou-se que as vacas descartadas voluntariamente seriam vendidas para abate. O aumento na vida útil foi obtido pela suposição de que a probabilidade de descarte involuntário fosse igual a zero.

Com base na identificação das características que afetam o lucro anual do sistema de produção proposto neste estudo (Tabela 2), foram escolhidas as seguintes características para compor o objetivo de seleção: produção de leite, gordura, proteína, idade ao primeiro parto, peso adulto e longevidade (vida útil).

Os componentes de receita e despesa do sistema foram:
- Receita: venda do leite, dos bezerros machos e fêmeas de 12 meses de idade e de vacas descartadas (abate).

- Custos: alimentação, novilhas de reposição e outros custos (sal mineral, custos veterinários, inseminação, manutenção de instalações).

Os valores econômicos foram calculados de acordo com o interesse de seleção de maximizar o lucro (receita - custo), dado um número fixo de animais no sistema, de acordo com Groen \& Van Arendonk (1997).

$\mathrm{O}$ valor econômico (VE), expresso em termos de lucro/animal, considerando-se o interesse em maximizar o lucro, mantendo-se fixo o número de animais (n) é:

VE lucro $=(1 / \mathrm{n}) *[\mathrm{~d}$ (receita anual $)-\mathrm{d}$ (custos anuais) $]$

Os custos fixos, uma vez que desaparecem no processo de obtenção das derivadas parciais para cada característica, não foram levados em consideração.

Tabela 2 - Características incluídas nos objetivos de seleção sistema de produção de leite com vacas $F_{1}$ (Holandês $x$ Zebu)

Table 2 - Traits considered to be included in breeding goals for the production system using $F_{1}$ cows (Holstein $x$ Zebu)

\begin{tabular}{ll}
\hline Característica & Efeito no lucro \\
Trait & Effect on profit
\end{tabular}

Produção de leite Milk production

Produção de gordura Fat production

Aumenta receita da venda do leite; afeta custos com alimentação. Increases milk revenues; influences feed costs.

Aumenta ou não a receita da venda do leite; afeta custos com alimentação. Increases or not revenues from milk sold; influences feed costs

Produção de proteína Protein production

\begin{abstract}
Aumenta ou não a receita da venda do leite; afeta custos com alimentação. Increases or not milk revenues.
\end{abstract}

Vida útil

Herd life

Peso adulto

Mature body weight

Diminui custos com reposição. Reduces replacement costs.

Aumenta receita com a venda de vacas de descarte. Aumenta custos com manutenção. Increases maintainence costs.

Idade ao primeiro parto Aumenta vida útil, diminuindo Age at first calving custos com reposição. Increases herd life, by reducing replacement costs.

Adaptado de Bittencourt (2000). Adapted from Bittencourt (2000).

R. Bras. Zootec., v.33, n.2, p.320-327, 2004 
O lucro marginal decorrente do aumento de uma unidade de cada característica, mantendo-se as outras constantes, foi obtido pela diferença entre a receita líquida anual esperada por vaca depois e antes do melhoramento genético, obtida pela PD, supondo-se o rebanho estabilizado e que estratégias ótimas de descarte fossem aplicadas no rebanho.

\section{Análises de sensibilidade}

Tendo em vista que a mistura cana + uréia constitui importante fonte de suplemento volumoso a ser fornecido na estação seca para vacas mestiças em lactação, os valores econômicos foram derivados considerando-se esta fonte de suplementação volumosa na seca. O uso associado da uréia mais sulfato de amônio com a cana forrageira serve de fonte protéica, recomendando-se uma mistura de $90 \%$ de uréia e $10 \%$ de sulfato de amônio, aplicada na base de $0,5 \mathrm{~kg}$ da mistura a cada $100 \mathrm{~kg}$ de cana fresca picada para adaptação e depois $1 \mathrm{~kg}$ a cada $100 \mathrm{~kg}$ de cana picada (Paranhos, 1987). O preço considerado para $1 \mathrm{~kg}$ de MS da mistura cana + uréia + sulfato de amônio foi de US\$ 0,022.

Dado que alguns laticínios têm proposto algum tipo de pagamento diferenciado para gordura e proteína, os valores econômicos foram derivados para três sistemas de pagamento:

1. Pagamento exclusivamente por volume (base).

2. Pagamento por volume e valor adicional de gordura: (aproximadamente o valor correspon- dente a 15 litros de leite (US\$3,00)/kg gordura acima de $3,1 \%$ ).

3. Pagamento por volume e valor adicional de gordura e proteína: (aproximadamente o valor correspondente a 15 litros de leite (US\$3,00)/kg gordura acima de $3,1 \%$ e o mesmo valor para cada $\mathrm{kg}$ de proteína acima de 3,0\%).

O preço do leite sofre flutuações devido, entre outros, às incertezas associadas à falta de políticas que regulamentem satisfatoriamente o setor. Por essa razão, foram realizadas análises de sensibilidade para avaliar o impacto de variações no preço do leite em (+) ou (-) $20 \%$ sobre os valores econômicos das características.

\section{Resultados e Discussão}

Tomando-se o sistema de pagamento vigente no momento (com base exclusivamente no volume), os valores econômicos para $\mathrm{V}, \mathrm{G}$ e $\mathrm{P}$ foram, respectivamente, US\$ 0,15; -US\$ 0,48 e -US\$ 0,31 (Tabela 3), refletindo que o aumento da produção de gordura e proteína por meio de seleção resultaria na redução do lucro da fazenda. O aumento na produção dos componentes do leite, em especial da gordura, acarretaria aumento nos requisitos nutricionais e, conseqüentemente, nos custos com alimentação. Resultados semelhantes foram obtidos por Madalena (2000) e Vercesi Filho et al. (2000), no Brasil. Contudo, os valores econômicos para gordura obtidos por estes autores, embora nega-

Tabela 3 - Valores econômicos expressos em US\$/kg para volume (V), gordura (G), proteína $(\mathrm{P})$ e peso adulto (PA) e expressos e, US\$/dia para idade ao primeiro parto (IPP) e vida útil (VU), de acordo com o esquema de pagamento

Table 3 - Economic values expressed in US\$/kg for volume $(V)$, fat $(G)$, protein $(P)$ and mature body weight (PA) and in US\$/day for, age at first calving (IPP) and herd life (VU), according to the payment scheme

\begin{tabular}{ccccccc}
\hline $\begin{array}{c}\text { Esquema de pagamento* } \\
\text { Payment scheme }\end{array}$ & $\mathrm{V}$ & $\mathrm{G}$ & $\mathrm{P}$ & $\mathrm{PA}$ & $\mathrm{IPP}$ & $\mathrm{VU}$ \\
\hline $\begin{array}{c}\text { 1 - base } \\
\text { (basis) }\end{array}$ & 0,15 & $-0,48$ & $-0,31$ & $-0,11$ & 0,08 & 0,04 \\
2 & 0,18 & 0,26 & $-0,29$ & $-0,10$ & 0,10 & 0,05 \\
3 & 0,19 & 0,26 & $-0,10$ & $-0,08$ & 0,11 & 0,06 \\
4 & 0,19 & $-0,48$ & $-0,30$ & $-0,10$ & 0,11 & 0,05 \\
5 & 0,11 & $-0,45$ & $-0,28$ & $-0,12$ & 0,05 & 0,02 \\
\hline
\end{tabular}

*1) Pagamento exclusivamente para volume; 2) pagamento para volume + valor adicional para gordura (U\$3,00/kg acima de 3,1\%); 3) pagamento para volume + valor adicional para gordura e proteína ( $U \$ 3,00 / \mathrm{kg}$ acima de $3,1 \%$ de gordura e US $\$ 3,00 / \mathrm{kg}$ de proteína acima de $3,0 \%$ ); 4) preço do leite (base) $+20 \%$; 5 ) preço do leite (base) $-20 \%$.

1) Payment exclusively for volume (basis); 2) Payment for volume and an additional value for fat ( $U \$ 3,00 / \mathrm{kg}$ above $3,1 \%)$; 3) Payment for volume and an additional value for fat and protein (U $\$ 3,00 / \mathrm{kg}$ above $3.1 \%$ of fat and US\$ 3.00/kg of protein above 3.0\%); 4) milk price (basis) $+20 \%$; 5) milk price (basis) $-20 \%$.

R. Bras. Zootec., v.33, n.2, p.320-327, 2004 
tivos, foram mais altos, porque foram calculados com base na produção de gordura acima de $3,1 \%$.

O valor econômico para IPP foi positivo (US\$ 0,08 ), indicando que para este sistema de produção em particular, em que as novilhas são adquiridas de outros rebanhos Zebus comerciais, o aumento em um dia adicional na idade ao primeiro parto não reduziria o lucro anual da fazenda. Este valor positivo reflete o aumento na receita do leite. Ao considerar-se que a novilha foi produzidano sistema, oresultado foi negativo (-US $\$ 0,29$ ), dado que dias adicionais na idade ao primeiro parto significa custos adicionais de manutenção (em especial, de custos com alimentação). Resultado similar foi obtido por Vercesi Filho et al. (2000).

O valor econômico para PA foi negativo (-US\$ 0,11). De acordo com Groen (1989), isto ocorre porque os custos marginais associados ao aumento dos requisitos para manutenção das vacas em lactação excederam o aumento marginal na receita obtida a partir das venda das vacas descartadas para abate. Uma característica importante associada ao peso corporal de vacas leiteiras é a capacidade de ingestão de alimentos, conforme extensivamente discutido por Veerkamp (1998). A questão de se aumentar ou não o peso dos animais deve ser discutida com base em suas relações com a capacidade de ingestão de alimentos e com a produção de leite. Em bovinos de raças leiteiras especializadas, com alto potencial para produção de leite, o aumento do consumo alimentar para minimizar os efeitos do balanço energético negativo que se estabelece nas fases iniciais da lactação é desejável. Neste caso, o aumento no tamanho do animal, acompanhado pelo aumento na capacidade de consumo alimentar pode ser favorável, dentro de um nível ótimo. Porém, levando-se em conta o potencial de produção de leite de vacas mestiças, não é esperado que a ocorrência deste balanço negativo represente um problema tão grave, como no caso de vacas de alta produção. Outro fator ponderado por Visscher et al. (1994) é que, em sistemas de produção a pasto, quando se impõe uma restrição na disponibilidade de volumosos, observa-se redução no valor econômico para peso adulto conforme as receitas líquidas sobre os custos fixos por unidade de volumoso excedem os custos marginais na produção de volumosos. Não se considerou no momento a possibilidade da inclusão desta característica em um objetivo de seleção, devido à falta de informações a respeito dos parâmetros fenotípicos e genéticos a este respeito na literatura brasileira. Além disso, os custos associados ao sistema de pastejo são menores quando comparados aos sistemas intensivos de alimentação. A inclusão do peso aos 12 meses de idade em um objetivo de seleção também poderia ser considerada. Este peso pode ser, de alguma forma, correlacionado com o PA e poderia influenciar o lucro proveniente da venda de bezerros desta categoria. Contudo, o preço de mercado de bezerros de um ano de idade é estabelecido com base na categoria de idade e grupamento genético, e não em seu peso (Anuário de Informações Estatísticas IEA, 2001, ANUALPEC, 2002). Por outro lado, considerando-se o lucro proveniente dos machos $F_{1}$ que permaneceram nos rebanhos comerciais para cria, recria e engorda, seria esperado que o peso econômico para características de desempenho ponderal fosse positivo, como demonstrado por Lôbo (1999), que obteve um valor econômico para o peso ao abate de $\mathrm{R} \$ 0,05 / \mathrm{kg}$, supondo que os machos fossem criados para abate na própria fazenda.

$\mathrm{O}$ valor econômico para um dia adicional de vida útil no rebanho foi de US $\$ 0,04$, semelhante ao obtido por Vercesi Filho et al. (2000). A vida útil é resultante da combinação das taxas de descarte voluntário e involuntário. O descarte involuntário neste caso poderia estar associado à combinação de várias características funcionais, como características de tipo relacionadas à adaptação ao sistema de pastejo (pés, pernas, úbere), resistência à doenças (em especial, à mastite e às doenças transmitidas por carrapatos), problemas reprodutivos etc. O melhoramento destas características poderia levar à redução de descarte involuntário e à otimização do descarte voluntário.

Os valores econômicos derivados para $\mathrm{V}, \mathrm{G}, \mathrm{P}$, IPP, PA e VU, quando a suplementação volumosa na época da seca foi a mistura de cana-de-açúcar + uréia, foram, respectivamente, 0,$16 ;-0,42 ;-0,26$; $-0,08 ; 0,08$ e 0,33 . Observa-se o aumento nos valores econômicos para $\mathrm{V}, \mathrm{G}, \mathrm{P}$ e VU, sendo este último mais acentuado. A redução do custo da suplementação volumosa na seca ocasionou o aumento da receita líquida da venda do leite, resultando no aumento dos valores econômicos destas características.

A mudança no sistema de pagamento introduzindo valores adicionais para gordura e proteína levaria ao aumento do valor econômico para $\mathrm{V}$ e G, enquanto para $\mathrm{P}$ seria, ainda, negativo. Isto se deve ao menor

R. Bras. Zootec., v.33, n.2, p.320-327, 2004 
teor original de proteína no leite (quando comparado ao teor de gordura). Neste caso, o aumento de $1 \mathrm{~kg}$ desta característica por meio de seleção não foi capaz de ocasionar diferença marginal positiva no lucro anual da fazenda. As análises de sensibilidade mostraram que os valores econômicos para V, IPP e $\mathrm{VU}$ foram os mais influenciados por mudanças no preço do leite.

Em razão da diversidade de circunstâncias de produção e incertezas associadas ao preço do leite, estudos adicionais devem ser realizados para avaliar o efeito da sensibilidade do valor econômico para $\mathrm{V}$ aos preços do leite e variação no sistema de pagamento sobre o retorno esperado de um programa de seleção. Os valores econômicos para IPP e características de desempenho ponderal deverão receber atenção especial, dado que estas características apresentam diferentes importâncias econômicas, de acordo com o nível de sistema de produção em que são expressas.

\section{Conclusões}

Para o sistema de pagamento vigente, com base exclusivamente no volume do leite entregue pelo produtor, a seleção para componentes não é economicamente vantajosa.

Nos casos em que a composição do leite é, de alguma maneira, contemplada no pagamento do leite, as produções de gordura e/ou proteína poderão ser incluídas em um objetivo de seleção.

A inclusão da idade ao primeiro parto e características de desempenho ponderal em um objetivo de seleção deve receber atenção especial, uma vez que estas características apresentam importâncias econômicas diferentes, de acordo com o nível de sistema de produção em que são expressas.

\section{Literatura Citada}

ANUÁRIO DE INFORMAÇÕES ESTATÍSTICAS DA AGRICULTURA (Série IEA). SP, Instituto de Economia Agrícola, São Paulo, 2000, 2001.

ANUALPEC 2001 - Anuário da Pecuária Brasileira. FNP Consultoria e Comércio, São Paulo, 2001. 359p.

BITTENCOURT, T.C.C. Estimativa de ponderadores econômicos para características de importância econômica em gado de corte, usando equações de lucro. Ribeirão Preto: Universidade de São Paulo, 2001. 60p. Tese (Doutorado em Genética) - Universidade de São Paulo, 2001.

BOICHARD, D. Estimation of the economic value of conception rate in dairy cattle. Livestock Production Science, v.24, p.187-204, 1990.
CARDOSO, V.L.; NOGUEIRA, J.R.; Van ARENDONK, J.A.M. Optimum replacement and insemination policies for crossbred cattle (Holstein Friesian x Zebu) in the south-east region of Brazil. Livestock Production Science, v.58, p.95-105, 1998.

DEKKERS, J.C.M. Estimation of economic values for dairy cattle breeding goals:bias due to sub-optimal management policies. Livestock Production Science, v.29, p.131-149, 1991.

DEKKERS, J.C.M.; TEN HAG, J.H.; WEERSINK, A. Economic aspects of persistency of lactation in dairy cattle. Livestock Production Science, v.53, n.3, p.237-252, 1998.

FEDERAÇÃO DA AGRICULTURA DO ESTADO DE SÃO PAULO - FAESP. Indicadores de eficiência técnica e econômica na produção de leite - Estado de São Paulo 1997. São Paulo, 1997. 178p.

GIBSON, J.P.; Van ARENDONK, J.A.M. Introduction to the design and economics of animal breeding strategies. Poland: Warsaw Agricultural University, 1998. 259p. (Lecture notes).

GROEN, A.F. Economic values in cattle breeding. Influence of production circumstances in situations without output limitations. Livestock Production Science, v.22, p.1-16, 1989.

GROEN, A.F.; STEINE, T.; COLLEAU, J.J. et al. Economic values in dairy cattle breeding, with special reference to functional traits. Report of an EAAP-working group. Livestock Production Science, v.49, p.1-21, 1997.

GROEN, A.F.; Van ARENDONK, J.A.M. Breeding programs. Wageningen: Wageningen Agricultural University, 1997. 98p. (Lecture Notes)

LÔBO, R.N.B. Programas de seleção para bovinos zebus de dupla aptidão. Belo Horizonte: Universidade Federal de Minas Gerais, 1999. 87p. Tese (Doutorado em Zootecnia) Universidade Federal de Minas Gerais, 1999.

LEMOS, A.M.; TEODORO, R.L.; MADALENA, F.E. Comparative performance of six Holstein-Friesian x Guzera grades in Brazil. 9. Stayability, herd life and reasons for disposal. Brazilian Journal of Genetics, v.19, p. 259-264, 1996.

LEMOS, A.M.; VERNEQUE, R.S.; TEODORO, R.L. et al. Efeito da estratégia de cruzamentos sobre características produtivas e reprodutivas em vacas do sistema mestiço do CNPGL-EMBRAPA. Revista Brasileira de Zootecnia, v.26, p.704-708, 1997.

MADALENA, F.E.; LEMOS, A.L.; TEODORO, R.L. et al. Dairy production and reproduction in Holstein-Friesian and Guzera crosses. Journal of Dairy Science, v.73, p.18721886, 1990a.

MADALENA, F.E.; TEODORO, R.L.; LEMOS, A.L. et al. Evaluation of strategies for crossbreeding of dairy cattle in Brazil. Journal of Dairy Science, v.73, p.1887-1901, 1990b.

MADALENA, F.E. A simple scheme to utilize heterosis in tropical dairy cattle. World Animal Review, v.74/75, p.17-25, 1993.

MADALENA, F.E. Valores econômicos para seleção de gordura e proteína do leite. Revista Brasileira de Zootecnia, v.29, n.3, p.678-684, 2000.

PARANHOS, S.B. Cana-de-açúcar. Cultivo e utilização. Campinas: Fundação Cargill, 1987. p.805-849.

PONZONI, R.W.; NEWMAN, S. Developing breeding objectives for Australian beef cattle production. Journal of Animal Production, v.49, p.35-47, 1989.

Van ARENDONK, J.A.M. A model to estimate the performance, revenues and costs of dairy cows under different production and price situations. Agriculture Systems, v.16, p.157-189, 1985. 
Van ARENDONK, J.A.M.; DIJKHUIZEN, A.A. Studies on the replacement policies in dairy cattle. III. Influence of variation in reproduction and production. Livestock Production Science, v.13, p.333-349, 1985.

VARGAS, B. Bio-economic modeling to support management and breeding of dairy cows in Costa Rica Wageningen: Wageningen University, 2000. 187p. Thesis (PhD) Wageningen University, 2000.

VEERKAMP, R.F.; HILL, W.G.; STOTT, A.W. et al. Selection for longevity and yield in dairy cows using transmitting abilities for type and yield. Journal of Animal Science, v.61, p.189-197, 1995.
VERCESI FILHO, A.E.; MADALENA, F.E.; FERREIRA, J.J. et al. Pesos econômicos para seleção de gado de leite. Revista Brasileira de Zootecnia, v.29, p.145-152, 2000.

VISSCHER, P.M.; BOWMAN, P.J.; GODDARD, M.E. Breeding objectives pasture based dairy production systems. Livestock Production Science, v.40, p.123-137, 1994.

Recebido em: 05/09/02

Aceito em: 23/06/03 